\title{
A regionalização do agronegócio da soja em Rondônia
}

Ricardo Gilson da Costa Silva Universidade Federal de Rondônia

p. $298-312$

\section{revista}

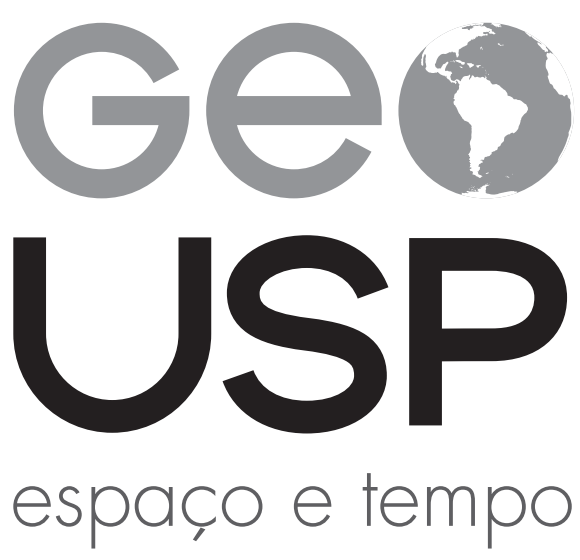

Volume 18, no 2 (2014)
Artigo disponível em:

http://www.revistas.usp.br/geousp/article/view/84534

Como citar este artigo:

COSTA SILVA, R. G. A regionalização do agronegócio da soja em Rondônia. GEOUSP - Espaço e Tempo (Online), São Paulo, v. 18, n. 2, p. 298-312, 2014.

\section{$(\mathrm{cc}) \overline{\mathrm{EY}}$}

Este artigo está licenciado sob a Creative Commons Attribution 3.0 License. 


\title{
A regionalização do agronegócio da soja em Rondônia
}

Ricardo Gilson da Costa Silva

\section{Resumo}

O avanço do agronegócio da soja na Amazônia brasileira resulta do processo de modernização agrícola derivado da ação do capital nos espaços rurais. No sul de Rondônia, há a regionalização produtiva da soja, que modifica as relações campo-cidade e se constitui no uso corporativo do território por empresas hegemônicas do agronegócio. A redução da população no campo e o crescimento das cidades são os impactos geográficos desse processo, que fragmenta o espaço rondoniense a partir da produção dessa commodity.

Palavras-chave: Rondônia. Regionalização produtiva. Agronegócio. Campo e cidade.

\section{The regionalization of soybean agribusiness in Rondonia}

\begin{abstract}
The advance of soy agribusiness in the Brazilian Amazon Region is a result of the agricultural modernization processes which derivates of the Capital in rural spaces. In the south of Rondonia, the productive regionalization of soy modifies the rural-urban relations and constitutes the corporative use of the territory by the hegemonic corporations of agribusiness. The reduction of the population in the rural areas and the enlargement of the cities are geographical impacts of this process which fragments the Rondonia's spaces from the production of its commodity.
\end{abstract}

Keywords: Rondonia. Productive Regionalization. Agribusiness. Rural-Urban Relations.

\section{Introdução}

Na Amazônia brasileira, expande-se a produção de commodities agrícolas que articula a região aos circuitos espaciais da produção globalizada. As políticas públicas e privadas de investimentos para a instalação de novos sistemas de engenharia e os estímulos à ocupação agrícola 
capitalista configurada em monoculturas de grande escala avançam na Amazônia Meridional, com fortes impactos territoriais nos eixos de penetração do Mato Grosso, a partir da rodovia BR-163 (Cuiabá-Santarém), no sudeste do Pará, no norte do Tocantins e no sul de Rondônia.

$\bigcirc$ movimento espacial do capital globalizado ganhou relevante expressão econômica e política a partir da década de 1990, quando a liberalização da economia brasileira abriu os caminhos para a transformação agrícola em todas as regiões, com significativos avanços nos cerrados e no bioma amazônico. Esses movimentos foram sistematizados no conceito de agronegócio, termo que expressa as relações dos diversos setores da economia sob a mobilização do produto agrícola operado pelos capitais agropecuário, industrial e bancário. Designa, portanto, a aproximação entre a agricultura e indústria ao trabalhar todos os momentos da produção e da circulação da mercadoria, com impactos nas dinâmicas sociais e territoriais agrárias e urbanas, principalmente em função da valorização e incorporação de terras à produção do agronegócio.

Por sua vez, esse pacto assenta-se na modernização conservadora da elite agrária brasileira e latino-americana, associada política e economicamente aos capitais das esferas urbanas (indústria, comércio e serviços, bancário e financeiro) com forte apoio do Estado, apresentando o agronegócio como o carro chefe do desenvolvimento econômico e da modernidade nos processos de globalização que avançam também nas áreas rurais menos dinamizadas da América Latina, a exemplo da Amazônia. $\bigcirc$ corolário geográfico é que a terra passou a ser um ativo globalizado para o capital nacional e internacional, cuja atuação territorial produz a expropriação do campesinato e suas formas coletivas de produção agrícola, amplia a degradação social e ambiental, e qualifica os conflitos agrários na escala global quando atinge os interesses das empresas multinacionais (Fernandes, 2008). ${ }^{1}$

No estado de Rondônia, objeto da análise desse texto, a inserção da produção de soja inaugura a formação dos espaços luminosos onde a expansão agrícola gesta uma particularidade no espaço agrário e regional, configurado na formação da região do agronegócio da soja, ao tempo que se constitui o uso corporativo do território pelas grandes empresas do capital globalizado, isto é, Amaggi e Cargill. $\bigcirc$ campo modernizado pelas commodities impõe às cidades sua reformulação em termos de funcionalidades, dado a demanda por serviços tecnológicos, créditos, assistência técnica, equipamentos, força de trabalho e outros insumos necessários à expansão da produção agrícola, ou seja, o agronegócio conforma um urbano funcional ao desenvolvimento das atividades produtivas.

Nessa ótica, o processo de globalização atinge Rondônia de forma fragmentada, articulando campo-cidade na produção da região da soja com a territorialização do capital. As ações dos atores hegemônicos realizam-se na consecução das verticalidades e das solidariedades organizacionais que tornam as cidades e os campos funcionais ao mercado global, inaugurando os espaços luminosos das commodities. A relevância desse processo também se expressa na

\footnotetext{
1 A produção da geografia do campesinato elaborada no âmbito da teoria geográfica brasileira analisa as diversas formas de expropriação, conflitos e resistência dos camponeses frente ao avanço do agronegócio, ampliando os estudos referentes às conflitualidades agrárias em outros países da América Latina. Nessa perspectiva, pesquisa as transformações no campo com forte crítica à suposta superioridade do agronegócio como modelo de desenvolvimento neoliberal agrícola, denunciando processos de subalternidades, preconceitos e expropriações a que estão sujeitas as formas coletivas de trabalho no espaço agrário, como a dos camponeses, dos ribeirinhos, dos extrativistas, dos indígenas e dos quilombolas, entre outras. No livro Campesinato e agronegócio na América Latina, há uma excelente síntese de alguns desses processos no Brasil, no Paraguai, na Argentina, na Bolívia, na Guatemala e no México.
} 
particularidade geográfica configurada na formação da região do agronegócio da soja, sendo esta a primeira atividade produtiva que de fato vai produzir uma fragmentação no espaço agrário rondoniense decorrente do processo de globalização.

\section{A modernização dos espaços agrícolas e as relações campo-cidade}

Na geografia brasileira crescem as pesquisas, debates e eventos acadêmicos referentes às temáticas e às relações campo-cidade, espaço urbano e rural. Discutem-se suas funcionalidades, especificidades, complementaridades geográficas, econômicas, culturais e sociais, caminhando para uma percepção indissociável dessas construções geográficas da sociedade que se acelera nas diversas regiões do Brasil. ${ }^{2}$

As mudanças socioespaciais assumem notoriedades com o período técnico-científico (Santos, 2008), considerando que no território certas especializações produtivas vão modificar a relação espacial que unem campo e cidade, ao inserir novos produtos e/ou técnicas que servem tanto para afastar ou para aproximar os elementos sociais que dão coesão ao território.

Em A urbanização brasileira, Santos (2005) problematiza as relações campo e cidade, argumentando a necessidade de um esforço teórico-metodológico que pudesse edificar um quadro conceitual compatível com as novas relações geoeconômicas, que tornavam essa separação (campo-cidade) limitada à compreensão da totalidade do território:

A cidade torna-se o lócus da regulação do que se faz no campo. É ela que assegura a nova cooperação imposta pela nova divisão do trabalho agrícola, porque obrigada a afeiçoar-se às exigências do campo, respondendo às suas demandas cada vez mais prementes e dando-lhe respostas cada vez mais imediatas. Como o campo se torna extremamente diferenciado pela multiplicidade de objetos geográficos que o formam, pelo fato de que esses objetos geográficos têm um conteúdo informacional cada vez mais distinto (o que se impõem, porque o trabalho no campo é cada vez mais carregado de ciência), tudo isso faz com que a cidade local deixe de ser a cidade no campo e transforme-se na cidade do campo [...] $\bigcirc$ consumo produtivo rural não se adapta às cidades, mas, ao contrário, adapta-as (Santos, 2005, p. 56/61).

A modernização da agropecuária/agricultura se torna um potente processo que modifica as configurações geográficas locais pelo fato de o campo acolher as atividades produtivas tecnológicas que impulsionam a produção de novas mercadorias, seja na verticalização da produção, em que emergem as agroindústrias, como na horizontalização das cadeias produtivas, produto da expansão do espaço agrícola articulado aos circuitos espaciais da produção, aumentando cada vez mais o intercâmbio entre campo e cidade.

Essas complexidades socioespaciais ganham novas feições no Brasil e são cada vez mais potencializadas pela modernização do território decorrente da reestruturação produtiva da agropecuária, fazendo ampliar as trocas econômicas intersetoriais e aprofundando, dessa for-

2 Algumas publicações recentes, sob óticas diferentes, retratam essa questão no Brasil: M. Sposito e Whitacker (2006); E. Sposito, M. Sposito e Sobarzo (2006), Elias (2003; 2006; 2012) e Elias e Pequeno (2006). 
ma, as relações do campo para com a cidade. Contudo, o comando produtivo dos espaços rurais modernizados assume relevância na dinâmica territorial urbana, sendo, pois, imperativo uma nova classificação desses fenômenos, os quais Santos (2005, p. 75-76) qualifica como regiões agrícolas com áreas urbanas e regiões urbanas com áreas rurais, ampliando a questão campo-cidade como totalidade espacial.

Nas regiões agrícolas a modernização da economia avança nos circuitos produtivos e fomenta as especializações territoriais, gerando processos econômicos, sociais e territoriais nas cidades, concomitante a uma tipologia de funções que alarga as complementaridades geográficas do espaço urbano e rural (Elias, 2003; Bernardes; Freire Filho, 2006). O campo que se moderniza demanda da cidade todos os insumos e implementos agrícolas necessários à expansão da produção, mas igualmente requer créditos e uma rede de serviços tecnológicos que impõe um novo conteúdo técnico ao território e ao sistema urbano. Portanto, não se tratam somente de trocas setoriais econômicas, mas da produção de um espaço urbano derivado das pautas emanadas dos espaços rurais, dada à emergência de novos usos e funcionalidades territoriais da modernização agrícola.

A modernização da agricultura avança no Brasil após a década de 1960, período em que a produção agrícola passa a se apoiar cada vez mais no uso de insumos tecnológicos (fertilizantes químicos, máquinas, tratores, e outras tecnologias), resultando em maiores produtividades dos fatores de produção e do trabalho. Segundo Graziano da Silva (1982) esse processo se dá somente quando o capital industrial se consolida e se torna hegemônico no Brasil, impondo à agricultura sua modernização da base técnica, deixando de ser um setor autossuficiente e sem maiores relações com a dinâmica da economia, ou seja, "a agricultura se converteu gradativamente num setor subordinado à indústria e por ela transformada" (p. 46), iniciando um processo de industrialização da agricultura que se realiza em duplo sentido: "o da elevação da composição técnica nas suas unidades de produção e o da subordinação do setor aos interesses do capital industrial e financeiro" (p. 46). Trata-se das mudanças na base técnica do processo produtivo que vai aproximar o setor agrícola do setor industrial, cujas complementaridades convergem para o controle do capital financeiro, expandido com as medidas de financiamento da produção.

Esse processo dar-se-á de forma heterogênea no Brasil, com maior densidade na Região Concentrada (Santos; Ribeiro, 1979; Santos; Silveira, 2005). ${ }^{3}$ Nas últimas décadas o fluxo de modernização avança para as regiões Centro-Oeste, Norte e Nordeste, realizando-se em manchas de modernização acompanhado pelo avanço da produção de soja e da agropecuária, ambas mercadorias destinadas, em seu maior volume, ao comércio exterior.

3 O conceito de região concentrada foi formulado por Milton Santos e Ana Clara Torres Ribeiro no final dos anos 1970, para caracterizar a formação de um espaço contínuo, abrangendo os estados do Sul e do Sudeste do Brasil, com alta densidade técnica e científica incorporada ao território, decorrente das mudanças econômicas e sociais nessas regiões. Na região concentrada, a produção e a circulação das mercadorias, os serviços tecnológicos e financeiros são intensos e centralizados pelas metrópoles de São Paulo, que mantém a primazia urbana, e do Rio de Janeiro, formando um espaço contínuo que se expressa no meio técnico-científico-informacional. Contemporaneamente, alguns estudos apontam a incorporação do Mato Grosso do Sul e do Mato Grosso à região concentrada, em função da intensidade do desenvolvimento do agronegócio (carnes e grãos, principalmente) e das transformações territoriais impostas pela dinâmica multiescalar dessas atividades produtivas. 
Bernardes (2009, p. 15) analisa a territorialização do capital nas áreas de expansão da soja no estado do Mato Grosso, e seu movimento espacial nos cerrados do Norte/Nordeste. São as fronteiras da agricultura moderna, designando a formação de uma região do agronegócio denominada Bamapito, que abrange o oeste baiano, o sudoeste e o sul do Piauí, o sul maranhense e o nordeste de Tocantins, onde os modernos sistemas técnicos instauraram verticalidades com a inovação e modernização da agricultura. Para o Mato Grosso, além da formação e expansão do complexo soja aprofunda-se a modernização da agropecuária associada aos circuitos espaciais de produção, que unindo agropecuária e indústria formam as cadeias de carne e grãos sob a hegemonia do capital industrial e financeiro (Bernardes; Aracri, 2010).

Elias e Pequeno (2006) estudam o avanço da soja no Nordeste, indicando a fragmentação do território a partir do agronegócio globalizado e as novas desigualdades sociais produzidas pelos feixes de modernização da agricultura. Recentemente, ao aprofundar as análises das transformações territoriais derivadas do avanço do agronegócio, Elias (2006) tem proposto que a gestão política desse processo se realiza nas cidades que a autora qualifica como Cidades do Agronegócio, designando aqueles espaços urbanos em que as atividades de gestão, controle e cooperação do processo de produção e circulação das commodities instauram novas territorialidades do capital a partir das solidariedades organizacionais, tornando-se hegemônicas sobre as demais atividades. Todavia, não são todas as cidades que ao produzirem soja e/ou outras commodities podem ser qualificadas nesse processo, mas somente as cidades que reúnem as variáveis hegemônicas do agronegócio globalizado, que fragmentam o espaço agrário e urbano, sendo, pois, espaços luminosos derivados da modernização agrícola e dos sistemas de objetos e sistemas de ações que fomentam novos conteúdos orgânicos e técnicos às áreas ou às regiões produtivas.

Nesse sentido, Elias (2011; 2012) propõe que a urbanização do território resultante desses fluxos de modernização agropecuária deve ser estudada à luz do que ela conceitua como regiões produtivas agrícolas (RPAs). ${ }^{4}$ Essa nova abordagem no âmbito da teoria geográfica deriva da reestruturação produtiva da agropecuária, que avança em regiões que há poucas décadas não haviam experimentado os vetores da modernização produtiva dos agentes hegemônicos do capital globalizado, articulando dialeticamente campo e cidade na produção de uma mercadoria destinada ao comércio internacional. Nesses espaços urbanos e rurais, o processo produtivo e as relações de trabalho capitalista estão vinculados às redes territoriais, redes de produção agroindustrial e agropecuária, ou seja, à formação dos circuitos espaciais produtivos e círculos de cooperação do agronegócio globalizado, o que permite visualizar a expansão do meio técnico-científico-informacional (Santos, 1996), ainda que de forma pontual ou em manchas, considerando que no espaço agrícola uma voraz fluidez territorial mobiliza profundas sinergias e complementaridades na relação campo-cidade

As atividades agrícolas e a produção agropecuária resultado do avanço do capital no campo criam diversas demandas nas pequenas cidades, que à luz dos eventos geográficos possibilita pensar as alterações realizadas do campo modernizado para as cidades, em várias esca-

4 Segundo Elias (2012, p. 3), "As RPAs são territórios produtivos do agronegócio globalizado. Dessa forma, são compostas tanto pelos espaços agrícolas como pelos urbanos escolhidos para receber os mais sólidos investimentos privados, formando os focos dinâmicos da economia agrária, ou seja, são áreas de difusão de vários ramos do agronegócio, palco de circuitos superiores do agronegócio globalizado". 
las geográficas da vida social. A análise se desenha na leitura do espaço agrário como campo preponderante da transformação territorial no estado de Rondônia, onde as escalas geográficas da produção se arquitetam na ampliação dos contextos dos lugares (Santos, 1996), estes cada vez mais porosos aos movimentos da circulação da economia globalizada.

As novas complementaridades entre campo e cidade são produzidas pelo avanço do agronegócio da soja que se constitui num vetor de modernização do território em Rondônia. A combinação geográfica resultante configura-se na regionalização da produção de soja no sul rondoniense, onde a homogeneidade espacial dessa atividade produtiva é potencializada pelo uso corporativo do território, dado que o capital controla o fluxo da produção, impondo suas demandas no contexto social e territorial.

\section{O agronegócio e a regionalização da soja em Rondônia}

Embora Rondônia assuma função primária na divisão territorial do trabalho no Brasil, considerando que sua relevância ainda se concentra na produção madeireira, mineral e agropecuária, a partir de 1997 a produção de soja emerge como a primeira commodity que vai de fato impor uma dinâmica territorial que une o global ao local, reconfigurando o espaço regional.

A mudança na composição técnica e orgânica do território torna-se uma condição estrutural e funcional para que as atividades produtivas destinadas ao mercado internacional assumam uma porção relevante do espaço agrário. Deve-se garantir a produção e os fluxos dessas mercadorias, de modo que a fluidez territorial (Arroyo, 2003) comparece como atributo primordial nas áreas produtoras de commodities.

Na Amazônia, o governo federal executou um conjunto de obras infraestruturais, impulsionando o capital multinacional a buscar novos locais para o investimento privado e, assim, "redesenhando o sistema de circulação das commodities para exportação" na região (Oliveira, 2006, p. 18). No pacote de investimentos constava a hidrovia Madeira-Amazonas, implantada em 1997, que vai delinear dois importantes processos no espaço agrário rondoniense, impondo uma lógica externa ao local. Primeiro, torna-se um evento geográfico de primeira grandeza (Santos, 1996) que ao se espacializar modifica as relações multiescalares dos agentes territoriais e do lugar onde se materializa. Esse sistema de ação traz para o espaço regional os signos da globalização quando é posta aos agentes locais a possibilidade do crescimento econômico, a partir da produção de uma mercadoria com potencialidade comercial no mercado internacional, subvertendo as formas pretéritas de uso do território. Segundo, constitui-se num sistema de objeto que permite o fluxo internacional da mercadoria globalizada, ao tempo que impõe a lógica territorial do capital nos lugares, onde as monoculturas avançam sobre a produção familiar com fortes repercussões geográficas na dinâmica do espaço do campesinato, as quais se traduzem na migração nos sentidos campo-campo e campo-cidade, com consequente crescimento urbano.

Nunes (2004) destaca que a hidrovia Madeira-Amazonas, que permite o transporte de grãos e outros insumos no trecho de $1.063 \mathrm{~km}$, de Porto Velho (RO) à Itacoatiara (AM), ligando os portos do Grupo Amaggi, e de Porto Velho a Santarém (PA), no percurso de 1.623 km, que serve aos portos da Cargill, ao potencializar a produção de soja em Rondônia e no noroeste do Mato Grosso proporcionou uma (re)estruturação do uso produtivo do espaço regional, 
funcionando como modal hidro-rodoviário (rodovia BR-364 e hidrovia) que articulou o espaço amazônico ao fluxo do agronegócio globalizado. Esse evento produziu uma nova configuração geográfica em Rondônia, cujo resultado é a regionalização da produção de grãos de soja, milho e arroz, que se consolida no sul do estado (Silva, 2005).

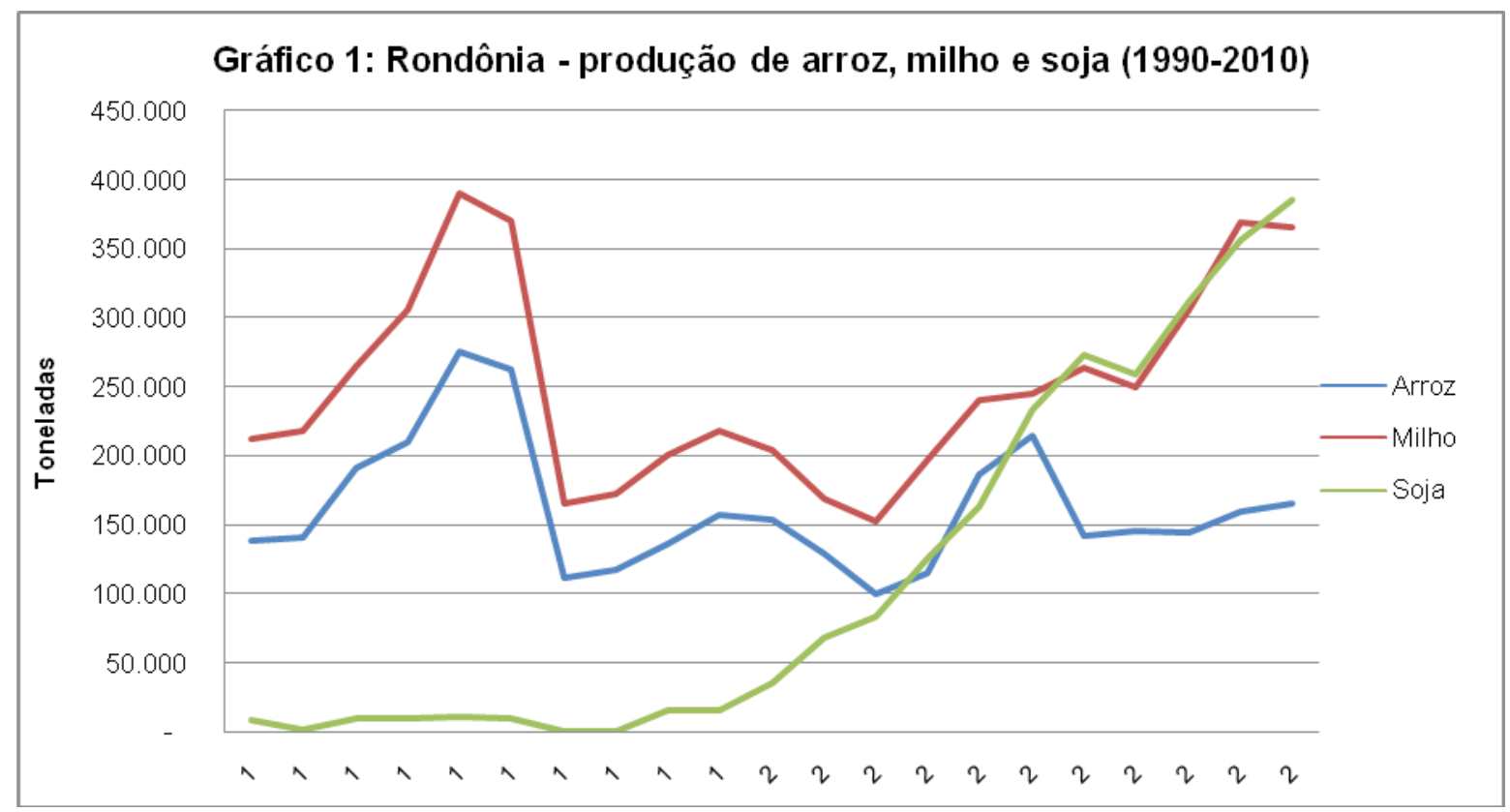

fonte: IBGE (2012).

Conforme o Gráfico 1, a produção de soja cresce substancialmente a partir de 1997 como consequência da hidrovia Madeira-Amazonas, a qual garantiu o fluxo dessa mercadoria ao mercado externo, assumindo como o principal grão produzido em Rondônia, seguido pelo milho e o arroz. A área plantada com soja, em 1997, era de apenas 636 hectares, registrando incremento considerável, em 1998, de 7.892 hectares, consolidando-se com 110.723 hectares em 2010. No mesmo período a produção saltou de 1.260 toneladas (1997) para 15.790 toneladas (1998), e, em 2010, para 385.388 toneladas (IBGE, 2012).

Cabe ressaltar que antes desse período a soja era insignificante como produto agrícola na economia estadual, pois, os elevados custos de produção e de transportes inviabilizavam toda ação para aumentar a presença dessa leguminosa no conjunto da agricultura. Ainda que se produzisse, seu consumo destinava-se ao mercado local e regional, e sua natureza, como mercadoria, era tão somente de grão, de uma leguminosa, e não de uma commodity, de uma mercadoria disputada no mercado global.

Essa transformação na natureza da mercadoria, que assume o estatuto de commodity, é de fundamental importância geográfica, pois, fez surgir uma espacialidade baseada na monocultura, modificando sobremaneira a paisagem rural, agora acrescida de elementos técnicos e científicos, ou seja, a monocultura vai produzir uma tecnificação e uma cientificação da paisagem, e em poucos anos regionaliza o espaço no sul de Rondônia. 


\section{Figura 1}

Rondônia: regionalização do agronegócio dos grãos (soja, arroz e milho) (t) $-2010$

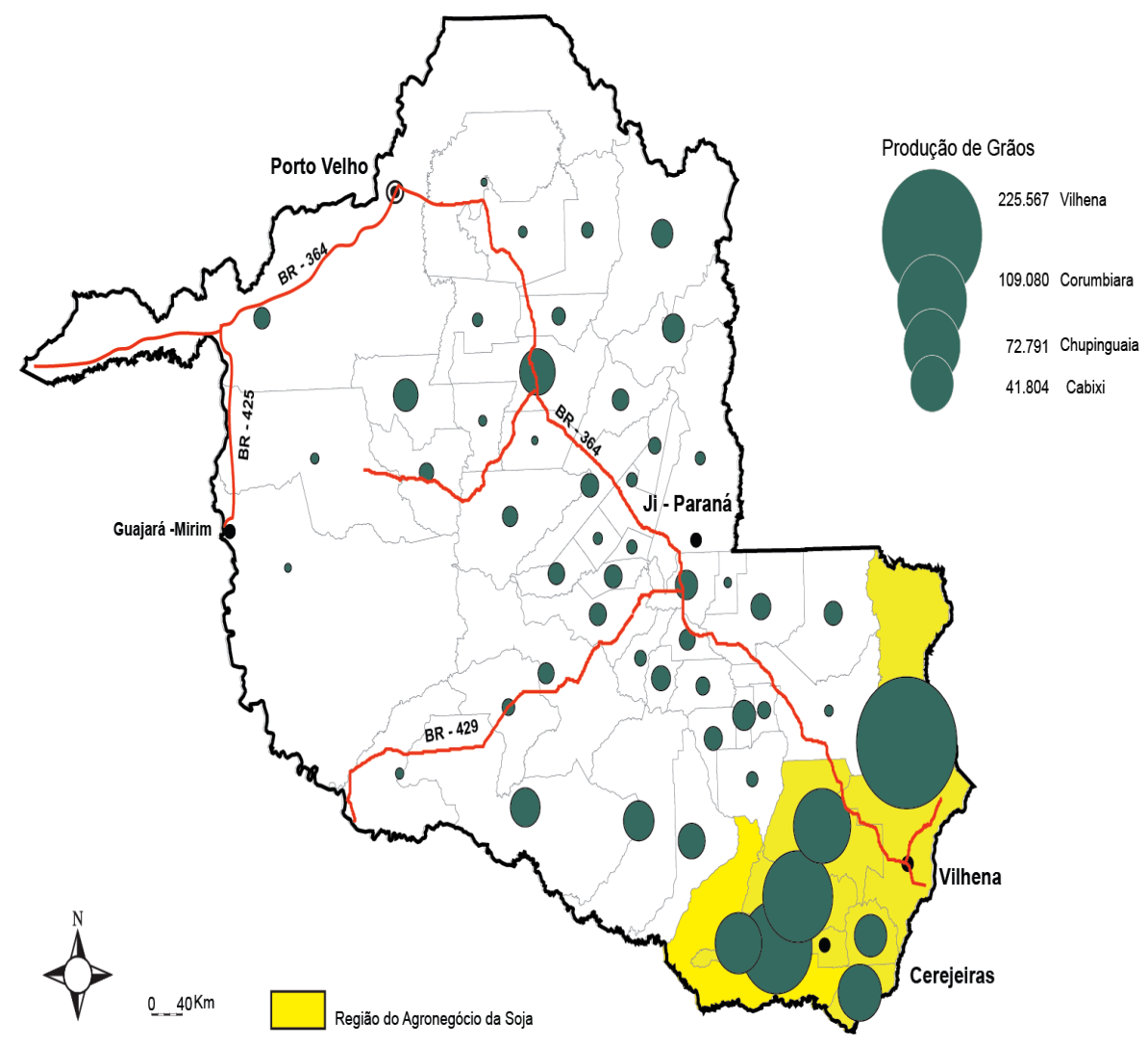

fonte: IBGE (2012). organização: Do autor. (Elaborado com Philcarto: http://philcarto.free.fr)

O fenômeno da regionalização do agronegócio dos grãos com o predomínio da soja (Figura 1) resultou na concentração e especialização de determinados tipos de atividades agropecuárias, ao passo que se constitui no empobrecimento da diversidade das mercadorias agrícolas relacionados à produção camponesa, dado o avanço do agronegócio na incorporação de áreas da produção familiar. Após a inserção da hidrovia a região do agronegócio se fortaleceu e se afirmou na economia regional ao concentrar 69\% dos grãos (soja, milho e arroz) produzidos em Rondônia. A soja impulsionou a produção das demais culturas agrícolas em função do sistema produtivo adotado, quando o cultivo do milho e do arroz, através do preparo do solo com a adição de insumos, melhorou substancialmente a produtividade da terra. A inserção tecnológica, científica e informacional no processo produtivo direto proporcionou à região a produção de 99\% da soja, 53\% do milho e 37\% do arroz expressos na forma de monoculturas que avançou sobre o espaço agrário no sul rondoniense (IBGE, 2012).

A agricultura científica requer um espaço mecanizado, sendo essa uma das manifestações importantes promovida pelas dinâmicas do agronegócio em Rondônia. Essa região apresentou, proporcionalmente, os maiores indicadores de propriedades com tratores, máquinas e outros insumos tecnológicos que alimentam a produção de soja e dos demais grãos. Dos es- 
tabelecimentos agropecuários em Rondônia somente 5,19\% destes tinham tratores, com uma média de 1,26 unidades por estabelecimento, mas na região do agronegócio esses dados eram, respectivamente, de $15 \%$ e 1.59 unidades de tratores, representando $19 \%$ do total dos tratores que havia no espaço agrário rondoniense (IBGE, 2006).

Para o município de Vilhena - a cidade do agronegócio - respectivamente esses indicadores eram de 14,40\% e de 1,76 tratores por estabelecimento, enquanto em Cerejeiras, o segundo produtor de soja, os dados eram de 11,09\% e 1,78 unidades. Em termos de armazéns e silos de grãos, Vilhena possui $22 \%$ das unidades e 35\% do volume da capacidade de armazenagem de Rondônia, sendo que a concentração se confirmou com o crescimento da produção dos grãos, transformando a composição técnica do território com a adição de novos sistemas de objetos para alicerçar o movimento espacial da mercadoria globalizada.

A geografia do agronegócio produziu o uso corporativo do território pelas empresas que participam do comércio internacional (Santos; Silveira, 2005), concomitante à regionalização da produção de grãos. Verifica-se o processo de "transformação substantiva do território, relacionado [...] aos circuitos de produção de grãos comandados pelos grandes agentes territoriais econômicos, como os grupos Amaggi e Cargill"' (Silva, 2010, p 128). Esses agentes hegemônicos vão impor uma forte especialização produtiva a partir das monoculturas, formas essas de ocupação do território até então estranhas no espaço rondoniense. Trata-se da inserção espacial do capital globalizado, notadamente nas áreas ocupadas pela pecuária e produção familiar que apresentavam estrutura fundiária e/ou condições edafoclimáticas favoráveis à expansão agrícola e que poderiam ser modificadas, e assim o foram, pelos mecanismos de coerção econômica e estratégias territoriais dos agentes hegemônicos. Contudo, as consequências geográficas também se configuram na alteração escalar das relações econômicas que já não mais se conformam na escala local. Permeiam no cotidiano da cidade e do campo os processos de verticalidades e de solidariedade organizacional do capital (Santos, 1996), e quando mobilizados na circulação da mercadoria esses lugares fragmentam seus usos aos comandos do capital globalizado, perdendo sua autonomia de significação (Santos, 2008, p. 59).

Desse modo, na escala local duas importantes alterações corroboraram à expansão do agronegócio em Rondônia. Primeiro, a área de produção de soja e dos demais grãos era ocupada pela pecuária extensiva, sobretudo, pecuária de corte com pouco incremento tecnológico. Nesse processo de substituição da atividade pecuária, a redução do rebanho bovino foi superior nos municípios onde a soja avançou, deslocando-os para as áreas norte e noroeste de Rondônia. A compra e os arrendamentos de terras, impulsionados pela capitalização que a agricultura globalizada promove nas áreas com pouco dinamismo econômico, foram outros mecanismo cruciais para que a regionalização da soja se concretizasse como uma fragmentação no espaço agrário rondoniense. Os produtores rurais migrantes do Mato Grosso, do Paraná e do Rio Grande do Sul, principalmente, formaram um emergente fluxo migratório seletivo e capitalizado, mobilizados pela incorporação de terras ainda com baixo valor de troca em relação às terras nas áreas de grande densidade do agronegócio, e de baixo custo na transformação orgânica do território (Silva, 2005).

A redução quantitativa da população no campo, especificamente, das familias camponesas constitui outro mecanismo da regionalização do agronegócio. A migração do campo para a cidade potencializou a emergente urbanização quando se trata somente de crescimento po- 
pulacional, concomitante à redução da produção familiar. A soja só não avançou nas áreas de relevo suavemente ondulado, que ficaram restritas às atividades agrícolas e à pecuária leiteira desenvolvidas pelos camponeses.

Reproduz-se na região do agronegócio processos socioterritoriais semelhantes aos ocorridos na Região Concentrada do Brasil, quando da realização da modernização conservadora da agricultura, sobretudo, relacionado à migração campo-cidade e campo-campo, e ao crescimento desordenado das cidades e do urbano, dado que o campesinato expropriado foi obrigado, mesmo no desenvolvimento da luta pela terra, a experimentar uma vez mais a migração como manifestação de sua desterritorialização.

\section{O crescimento das cidades na região do agronegócio}

$\bigcirc$ sul de Rondônia, onde se consolida a regionalização do agronegócio da soja, é formado por sete municípios, cuja centralidade se dá sob o comando de Vilhena. Destaca-se na geografia urbana dessa região a formação de pequenos municípios que apresentam uma taxa de urbanização de 80\%, maior que a média de Rondônia (73\%), e uma taxa de "ruralização" de 20\%, menor que a do estado (27\%). Todavia, ganha relevância nesses números a forte queda na população rural no conjunto dos municípios, no período de 2000 a 2010 (Tabela 1).

\section{Tabela 1}

Municípios da região do agronegócio - Rondônia - 2013

\begin{tabular}{|c|c|c|c|c|c|c|c|c|}
\hline \multirow{2}{*}{$\begin{array}{c}\text { município/ } \\
\text { estado }\end{array}$} & \multicolumn{5}{|c|}{ população (2010) } & \multicolumn{3}{|c|}{$\begin{array}{l}\text { variação \% } \\
(2000-2010)\end{array}$} \\
\hline & total & urbana & rural & $\begin{array}{l}\text { urb. } \\
(\%)\end{array}$ & rur. (\%) & total & urbana & rural \\
\hline Vilhena & 76.187 & 72.212 & 3.975 & 95 & 5 & 42 & 43 & 33 \\
\hline $\begin{array}{l}\text { Colorado do } \\
\text { Oeste }\end{array}$ & 18.602 & 13.666 & 4.936 & 73 & 27 & -15 & -6 & -33 \\
\hline Cerejeiras & 17.030 & 14.420 & 2.610 & 85 & 15 & -6 & -3 & -22 \\
\hline Corumbiara & 8.802 & 2.590 & 6.212 & 29 & 71 & -16 & 25 & -26 \\
\hline Cabixi & 6.309 & 2.693 & 3.616 & 43 & 57 & -16 & 1 & -25 \\
\hline Chupinguaia & 8.304 & 3.670 & 4.634 & 44 & 56 & 50 & 88 & 30 \\
\hline $\begin{array}{l}\text { Pimenteiras do } \\
\text { Oeste }\end{array}$ & 2.322 & 1.297 & 1.025 & 56 & 44 & -8 & -7 & -9 \\
\hline $\begin{array}{l}\text { região do } \\
\text { agronegócio }\end{array}$ & 137.556 & 110.548 & 27.008 & 80 & 20 & 15 & 25 & -15 \\
\hline Rondônia & 1.560 .501 & 1.142 .648 & 417.853 & 73 & 27 & 13 & 29 & -16 \\
\hline
\end{tabular}

fonte: IBGE (2012). 
A regionalização do agronegócio exige uma rede urbana funcional à expansão econômica e ideológica. A população dessa região é de 137.556 habitantes e representa somente 8,8\% da população de Rondônia. No ranking estadual, a cidade de Vilhena ocupa a quinta posição em termos populacionais, apresentando a maior taxa de urbanização (95\%), uma das maiores variações de crescimento populacional (42\%) e uma taxa de crescimento anual, no período de 2000 a 2010, de 3,58\% a.a, enquanto a de Rondônia foi de 1,24\%. No conjunto desses números, temos a formação de uma região com forte crescimento urbano derivado da modernização do espaço agrícola, cujo comando é assumido pela cidade de Vilhena, a maior produtora de soja e de milho.

Nessa região, a atividade econômica sempre se destacou pela presença da pecuária de corte, combinada com uma estrutura fundiária formada por médias e grandes propriedades, estabelecendo elos estreitos com as atividades urbanas, sobretudo as dos setores comerciais e de serviços ligados à agropecuária. Mas o avanço do agronegócio também atingiu o espaço do campesinato, e a migração campo-cidade se constitui num intenso processo de redução da agricultura camponesa que se vê forçada a vender ou arrendar suas terras em função da pressão do agronegócio. Essa foi a situação geográfica que se configurou em municípios com forte presença camponesa como Cerejeiras, Corumbiara, Colorado do Oeste e Cabixi, onde o capital provocou a redução populacional com taxas líquidas muito superior à média estadual (-16\%), quando o espaço agrário desses municípios perdeu de 22\% a 33\% da população (Tabela 1).

Esses mecanismos de monopolização do território pelo capital (Oliveira, 1991) ocorrem pela valorização do hectare de terras agriculturáveis que são potencializados pelo agronegócio, donde o campesinato é forçosamente inclinado a arrendar suas terras pelo valor monetário que os agentes do agronegócio (os produtores capitalizados) se propõem a pagar, o que em muitos casos é superior à renda que a família produz. Em outros casos, as terras são vendidas, e a trajetória das famílias camponesas se destina à ocupação de novas áreas de menor valor econômico, expandindo a fronteira agropecuária como atualmente se registra no norte e noroeste rondoniense, capitalizando essas famílias e reproduzindo socialmente o campesinato. Trata-se da produção do território do agronegócio, concomitante à redução do território do campesinato, e o caminho da população do campo é a cidade ou as demais áreas rurais de Rondônia onde afloram os conflitos agrários (Nascimento, 2008).

A cidade de Vilhena assume o comando e a gestão da produção de soja. Os equipamentos urbanos são acrescidos de agências bancárias, cooperativas de créditos, lojas especializadas em prestação de serviços tecnológicos que ajudam a construir uma solidariedade organizacional do capital (Elias, 2003). Como centro de logística Vilhena concentra as principais empresas de transportes de grãos, as empresas de maquinários e a assistência técnica que completa a sua função de centro local da economia urbana do agronegócio (Lus, 2012). Consolida-se tanto o consumo produtivo quanto o consumo consumptivo, transformando a cidade no espaço da regulação do que se faz no campo, dado que as complementaridades campo-cidade tornam-se indissociáveis. Desse modo, o uso corporativo do território realiza-se sob o comando dos agentes hegemônicos, que em Vilhena e em Cerejeiras esses papéis são assumidos pelas tradings Amaggi e Cargill, que controlam a produção, impondo preços e outros mecanismos econômicos e políticos para assegurar o controle regional da circulação da mercadoria. 
Outra dimensão importante da urbanização da região do agronegócio reside na sua ascensão econômica no espaço rondoniense. Dentre as principais empresas exportadoras de Rondônia, a Cargill Agrícola e a Amaggi Exportação e Importação ocupavam, respectivamente, o $1^{\circ}$ e o 40 lugar no ranking estadual, representando 29,17\% das exportações no ano de 2011 (Rondônia, 2012). Decorre desse processo a necessidade das cidades se ajustarem às demandas do campo modernizado e à gestão do espaço pelas empresas hegemônicas do agronegócio. A combinação entre território, normas e informações faz com que o capital componha na cidade os espaços formativos, espaços de aprendizagem que proporcionam a expansão profissional e a interação dos agentes econômicos referentes aos mecanismos tecnológicos, econômicos e políticos de reprodução do agronegócio.

A configuração geográfica resultante da regionalização do agronegócio foi o crescimento urbano, com a emergência do fenômeno das cidades do agronegócio (Elias, 2006), pois, a modernização da agricultura produziu transformações socioespaciais importantes nas pequenas e médias cidades onde esses processos se territorializaram. Nas espacialidades urbanas o uso do solo e sua compartimentação reproduzem, ainda que de forma embrionária, os modos de vida das metrópoles regionais e nacionais, seja na verticalização urbana, onde surgem os edifícios residenciais carregados de propaganda e de signos da modernidade, ou nos loteamentos residenciais fechados, reproduzindo, em ambos os casos, certa segregação socioespacial.

Nesse aspecto, o avanço do agronegócio da soja produziu em Rondônia o que Santos e Silveira (2005) denominaram espaços luminosos, pois, na adição de tecnologias e de novas próteses no território o meio geográfico evoluiu, ainda que em manchas ou pontos, para um meio técnico-científico-informacional (Santos, 1996), dada à incorporação do conhecimento científico às formas e aos processos produtivos que impõem ao campo e à cidade uma nova composição técnica e orgânica do espaço. Sob os feixes das forças da modernização tecnológica do campo as cidades transformam-se para se adequar a essas novas verticalidades, expressas nas dinâmicas de interiorização e de crescimento urbano vinculadas à expansão geográfica do agronegócio.

\section{Considerações finais}

$\mathrm{Na}$ Amazônia brasileira e tomando como componente empírico a produção de soja em Rondônia, a configuração espacial era tida como obstáculo à inserção de atividades produtivas, em função das lacunas que separavam produção-circulação, ou seja, as dimensões qualitativas de espaço-tempo necessárias à produção de uma mercadoria globalizada.

$\mathrm{Na}$ atualidade, a configuração de redes territoriais parece suplantar, para os agentes econômicos, essa dicotomia na perspectiva do mercado. Novos fixos e fluxos reordenam a função do espaço, agora, um espaço cujas ações concretas não resultam do contexto local, mas têm uma amplitude que articula ações locais, regionais e globais. Transforma-se a escala de produção e de ação conferindo uma renovada materialidade ao espaço e a seu conteúdo histórico.

O espaço de produção da soja fica no sul de Rondônia, em que a cidade de Vilhena assume primazia como centro produtor e gestor da região do agronegócio. A incorporação de áreas de pastagem convertidas em áreas de grãos foi a primeira mudança exponencial na paisagem agrícola que inaugurou o espaço das commodities, ampliando-o para os demais municípios do sul de Rondônia. 
Um componente importante derivado da modernização dos espaços agrícolas é o crescimento das cidades e sua taxa de urbanização. As empresas que atuam de forma corporativa no território impõem demandas às cidades para atender ao campo modernizado pela agricultura do mercado global, ampliando as complementaridades setoriais desses espaços. A formação da região do agronegócio da soja em Rondônia se destaca como espaço da produção globalizada, articulando campo e cidade na fragmentação do território.

A contradição que devemos apontar são os impactos desse movimento na reconcentração fundiária em Rondônia, posto que a agricultura camponesa ainda é predominante no espaço agrário, mas que continuamente se desloca internamente para novas sub-regiões de expansão agropecuária e florestal, criando instabilidades no território. A questão posta é a da fragmentação do espaço derivado das atividades produtivas globalizadas, onde a inserção espacial do capital tende a ser hegemônica, pressionando e expropriando familias camponesas.

\section{Referências}

ARROYO, M. El territorio brasileño y la internacionalización de los circuitos de producción. In: BERTONCELLO, R.; CARLOS, A. F. A. (Orgs.). Procesos territoriales en Argentina y Brasil. Buenos Aires: Instituto de Geografía, Facultad de Filosofía y Letras-UBA, 2003. p. 315-336.

BERNARDES, J. A. Fronteiras da agricultura moderna no cerrado Norte/Nordeste: descontinuidades e permanências. In: BERNARDES, J. A.; BRANDÃO FILHO, J. B. (Orgs.). Geografias da soja II: a territorialização do capital. Rio de Janeiro: Arquimedes, 2009. p. 13-39.

; ARACRI, L. A. S. (Orgs.). Espaços e circuitos produtivos: a cadeia carne/grãos no cerrado mato-grossense. Rio de Janeiro: Arquimedes, 2010.

; FREIRE FILHO, O. L. (Orgs.). Geografias da soja: BR-163 fronteiras em mutação. Rio de Janeiro: Arquimedes, 2006.

ELIAS, D. Relações campo-cidade, reestruturação urbana e regional do Brasil. COLÓQUIO INTERNACIONAL DE GEOCRÍTICA, 12., 2012, Bogotá. Disponível em: <www. ub.edu/geocrit/coloquio2012/actas/07-D-Elias.pdf>. Acesso em: 25 jul. 2014.

Agronegócio e novas regionalizações no Brasil. R. B. Estudos Urbanos e Regionais, v. 13, n. 2, p. 153-167, nov. 2011.

- Globalização e fragmentação do espaço agrícola do Brasil. Scripta Nova. Revista electrónica de geografia y ciencias sociales. Barcelona: Universidad de Barcelona, v. X, n. 218 (03), 1 ago. 2006. Disponível em: <http://www.ub.es/geocrit/sn/sn-218-03.htm>. Acesso em: 25 jul. 2014.

Globalização e agricultura: a região de Ribeirão Preto. São Paulo: Edusp, 2003.

; PEQUENO, R. (Orgs.). Difusão do agronegócio e novas dinâmicas socioespaciais. Fortaleza: Banco do Nordeste do Brasil, 2006. 
FERNANDES, B. M. (Org.). Campesinato e agronegócio na América Latina: a questão agrária atual. São Paulo: Expressão Popular, 2008.

GRAZIANO DA SILVA, J. G. A modernização dolorosa: estrutura agrária, fronteira agrícola e trabalhadores rurais no Brasil. Rio de Janeiro: Zahar, 1982.

IBGE. Instituto Brasileiro de Geografia e Estatística. Produção Agrícola Municipal - PAM. Rio de Janeiro, 2012. Disponível em: <http://www.sidra.ibge.gov.br>. Acesso em: 25 jul. 2014.

. Censo Demográfico 2010. Rio de Janeiro, 2010.

. Censo Agropecuário - 2006: Brasil, grandes regiões e unidades da federação. Rio de Janeiro, 2006.

LUS, D. A. Dinâmica socioespacial do agronegócio em Vilhena: uma análise sobre a expansão da fronteira tecnológica. Dissertação (Mestrado em Geografia) - Universidade Federal de Rondônia, Porto Velho, 2012.

NASCIMENTO, M. L. Reorganização dos espaços de produção agrícola da soja: análise dos municípios de Cerejeiras, Corumbiara e Pimenteiras do Oeste-RO (1990-2008). Dissertação (Mestrado em Geografia) - Universidade Federal de Rondônia, Porto Velho, 2008.

NUNES, D. D. Hidrovia do Madeira: (re)configuração espacial, integração e meio ambiente. Tese (Doutorado em Desenvolvimento Socioambiental) - Núcleo de Altos Estudos Amazônicos, Universidade Federal do Pará, Belém, 2004.

OLIVEIRA, A. U. A Amazônia e a nova geografia da produção de soja. Terra Livre, Goiânia, ano 22, v. 1, n. 26, p. 13-43, jan./jun., 2006.

. A agricultura camponesa no Brasil. São Paulo: Contexto, 1991.

RONDÔNIA. Secretaria de Estado do Desenvolvimento Econômico e Social. Indicadores do Agronegócio 2010/2011. Porto Velho, 2012.

SANTOS, M. Espaço e método. 5. ed. São Paulo: Edusp, 2008[1985].

A urbanização brasileira. 5. ed. São Paulo: Edusp, 2005[1993].

A natureza do espaço: técnica e tempo, razão e emoção. São Paulo: Hucitec, 1996.

; RIBEIRO, A. C. T. O conceito de região concentrada. Rio de Janeiro: UFRJ/IPPUR/ Departamento de Geografia, 1979. Mimeo.

; SILVEIRA, M. L. O Brasil: território e sociedade no início do século XXI. 8. ed. Rio de Janeiro/São Paulo: Record, 2005.

SILVA, R. G. C. Território e globalização: impactos em Rondônia - Amazônia Meridional. In: ARROYO, M.; ZUSMAN, P. (Orgs.). Argentina e Brasil: possibilidades e obstáculos no processo de integração territorial. São Paulo: Humanitas, 2010. p. 117-139. 
Avanços dos espaços da globalização: a produção de soja em Rondônia. Dissertação (Mestrado em Desenvolvimento Regional e Meio Ambiente) - Universidade Federal de Rondônia, Porto Velho, 2005.

SPOSITO, E. S.; SPOSITO, M. E.; SOBARZO, O. (Orgs). Cidades médias: produção do espaço urbano e regional. São Paulo: Expressão Popular, 2006.

SPOSITO, M. E.; WHITACKER, A. M. (Orgs). Cidade e campo: relações e contradições entre o urbano e rural. São Paulo: Expressão Popular, 2006. 